\title{
Removal of Chylomicron Remnants from the Bloodstream is Delayed in Aged Subjects
}

\author{
Carmen G. Vinagre ${ }^{1,2}$, Fatima R. Freitas ${ }^{1}$, Carlos H. de Mesquita ${ }^{3}$, Juliana C Vinagre ${ }^{1}$, Ana \\ Carolina Mariani $^{2}$, Roberto Kalil-Filho ${ }^{1}$, Raul C. Maranhão, ${ }^{1,4}$ \\ ${ }^{1}$ Heart Institute (InCor) of Medical School Hospital, University of São Paulo, São Paulo, Brazil. \\ ${ }^{2}$ University of Santo Amaro, São Paulo, Brazil \\ ${ }^{3}$ Institute of Nuclear Research, University of São Paulo, São Paulo, Brazil \\ ${ }^{4}$ Faculty of Pharmaceutical Sciences, University of São Paulo, São Paulo, Brazil
}

[Received May 16, 2017; Revised September 23, 2017; Accepted October 3, 2017]

\begin{abstract}
Dietary fats absorbed in the intestine are transported in the circulation as chylomicrons and remnants that have atherogenic potential. Although postprandial lipidemia is increased in older subjects, the specific chylomicron metabolism has not been explored in older subjects nor compared to young subjects, which is the focus of this study. After a $12 \mathrm{~h}$ fast, artificially-made emulsions similar to lymph chylomicrons and doubly labeled with radioactive cholesteryl esters and triglycerides were intravenously injected in 23 older (66 \pm 4 years) and 20 young ( $24 \pm 3$ years) subjects. Sequential blood samples were collected to determine fractional clearance rates (FCR, in $\mathrm{min}^{-1}$ ) by compartmental analysis. Older subjects had higher LDLcholesterol $(\mathbf{p}<\mathbf{0 . 0 0 1})$ and triglycerides $(\mathrm{p}<\mathbf{0 . 0 0 0 1})$ than young subjects; HDL-cholesterol presented no difference. The emulsion cholesteryl-ester FCR was lower in older subjects compared to the young ( $p=0.0001$ ). The emulsion triglyceride FCR did not differ in the two groups. Tested in vitro, however, the lipolysis of the emulsion triglycerides was less intense in the older than in the young subjects. As delayed removal of remnants, indicated by the pronouncedly smaller cholesteryl ester FCR, is related to the presence of cardiovascular diseases, this can be a risk factor which could accelerate atherogenic complications occurring in aged subjects
\end{abstract}

Key words: Aging and atherosclerosis, chylomicron remnants, cholesterol and aging, triglyceride, emulsions

Chylomicrons are the lipoproteins in which dietary fats and cholesterol absorbed in the small intestine are transported in the lymph and in the bloodstream. On the endothelium surface of capillaries, chylomicron triglycerides are broken-down by lipoprotein lipase (LPL); the lipolysis products, fatty acids and glycerol are stored in adipose and muscle tissues and the resulting triglyceride-depleted remnants are finally taken-up by the liver [1, 2]. Although chylomicron remnants have atherogenic potential [3], this metabolism is difficult to evaluate. Time-consuming postprandial lipemia tests consist in the ingestion of a standard fatty meal followed by hours-long blood sampling to determine lipid marker concentration [2].

The aging process is accompanied by a rise in LDLcholesterol due to a decrease in the capacity of the older to remove LDL $[4,5]$. This is probably due to a loss in the functional capacity of the LDL receptors that remove the lipoprotein from the circulation [6]. It has also been reported that postprandial lipemia [4,5] and serum

*Correspondence should be addressed to: Dr. Raul C. Maranhão, Instituto do Coração (InCor) do Hospital das Clínicas, São Paulo, SP 05403-000, Brazil. e-mail: ramarans@usp.br

Copyright: () 2017 Vinagre CG et al. This is an open-access article distributed under the terms of the Creative Commons Attribution License, which permits unrestricted use, distribution, and reproduction in any medium, provided the original author and source are credited. 
concentration of retinyl palmitate $[7,8]$ added to the test fat load as remnant labels are increased in aged subjects. The chylomicron-like emulsions method is straightforward and more precise in evaluating this metabolism, allowing for plasma kinetics analysis $[9,10,11]$. In this approach, artificially-made emulsions with similar composition to that of lymph chylomicrons and doubly labeled with radioactive cholesteryl esters and triglycerides are intravenously injected. Sequential blood samples are then collected to determine the decay curves of both radioisotopes and fractional clearance rates by compartmental analysis $[11,12,13]$. The curves of cholesteryl esters, that are not independently removed from the emulsion particles, stand for remnant removal. Meanwhile, triglyceride curves mirror the lipolysis process and the removal from the plasma of the emulsion triglycerides that were not broken-down and remain in the particles until final uptake of the remnants by the liver [11,14]. This study investigated in older subjects, as compared to young subjects, the simultaneous lipolysis and remnant removal of the chylomicron-like emulsions.

\section{MATERIALS AND METHODS}

Twenty volunteers of both genders, aged $<30$ years and 23 aged $>60$ years, all healthy, were selected from the Checkup Clinics and admitted to the Lipid Metabolism Laboratory of the Heart Institute (HC-FMUSP) in São Paulo, Brazil. Participants did not have diabetes, glucose intolerance (fasting glycemia $<100 \mathrm{mg} / \mathrm{dL}$ ) or arterial hypertension, and were normolipidemic, non-obese and sedentary. None were under any medication, had no alcohol abuse history and they are non-smokers.

The study protocol was approved by the Ethics Committee of the University of São Paulo Medical School Hospital. An informed-signed consent was obtained from each participant.

Serum lipid analysis was performed with standard commercial kits. The chylomicron-like emulsion labeled with cholesteryl $\left[1-{ }^{14} \mathrm{C}\right]$ oleate $(\mathrm{CE})$ and $\left[9,10-{ }^{3} \mathrm{H}\right]$ glycerol-tri-oleate (TG) was prepared by ultrasonic irradiation, followed by two-step ultracentrifugation, as described previously $[11,12,13]$, and then sterilized by passage through a 0.2 micrometer filter. The emulsion was prepared in four batches; each batch was injected in subjects of the both studied groups.

The volume of the emulsion to be injected into the study subjects was calculated to obtain $148 \mathrm{kBq}(4 \mu \mathrm{Ci})$ of ${ }^{3} \mathrm{H}$-TG and $74(2 \mu \mathrm{Ci})$ of ${ }^{14} \mathrm{C}$-CE. The emulsion was injected intravenously after $12 \mathrm{~h}$ overnight fast. Blood was collected at pre-established intervals during $60 \mathrm{~min}$ for radioactive counting and determination of the fractional clearance rates (FCR, in $\mathrm{min}^{-1}$ ) of the two radioactive emulsion labels by compartmental analysis model $[10,11,12]$, according to a modification of the model proposed by Redgrave and Zech [14]. The fitting of experimental curve of the present study shows the following profile: both radioactivity decay curves $\left({ }^{14} \mathrm{C}\right.$ $\mathrm{CE}$ and ${ }^{3} \mathrm{H}$-TG) show a rapid decay followed by a slow decay. Finally, the curve tends to a plateau out or to a smooth increase suggesting recycling of the radioactivity compounds incorporated into VLDL secreted by the liver. These features are similar to the biphasic plasma decay curve of natural chylomicrons [10]. The experimental points of plasma radioactivity measurements at the various sampling times $\left(\mathrm{t},{ }^{14} \mathrm{C}\right.$ and $\left.{ }^{3} \mathrm{H}\right)$ were fitted to the compartment model shown in Figure 1. The model proposed by Redgrave and Zech [14] does not consider a direct output of the compartments (C1) and (C5), but the initial absence of a plateau in the decay curve, as shown previously [10], suggests that a fraction of the injected particles is removed directly from plasma by the liver or other tissues [13]. The precision of parameters of the kinetic model presented an averaged coefficient of variation of $4.9 \% \pm 10.2 \%$.

The dose for the subjects of the radioactive material was $0.069 \mathrm{mSv}$ and 0.013 for ${ }^{14} \mathrm{C}-\mathrm{CE}$ and ${ }^{3} \mathrm{H}-\mathrm{TG}$, respectively, much lower than the permitted $1 \mathrm{mSv}$ limit for radioactive intake for individuals, as determined by the International Commission on Radiological Protection [15].

In vitro post-heparin lipoprotein lipase (LPL) activity in the plasma was determined after $12 \mathrm{~h}$ fasting on the day after the kinetic studies [16,17], using as substrate a chylomicron-like emulsion labeled with glycerol tri $\left[{ }^{3} \mathrm{H}\right]$ oleate. The plasma samples, collected 10 minutes after an injection of heparin $(10 \mathrm{U} / \mathrm{kg} \mathrm{BW})$, and the emulsion were incubated at $37^{\circ} \mathrm{C}$ for pre-established intervals during $180 \mathrm{~min}$. The lipids were then extracted and separated by thin-layer chromatography. The radioactivity present in the triglyceride band was measured and the area under the curve (AUC) was calculated.

Data was represented as mean \pm standard deviation (SD). Comparisons between two groups were assessed using the independent $t$-test. $P$ values less than 0.05 were considered statistically significant.

\section{RESULTS}

Table 1 shows the characteristics of the participant subjects of both groups. The two groups did not differ in respect to fasting glucose, $\mathrm{BMI}$, and in number of male or female gender. 
Table 1. Plasma lipids and in vitro lipolysis measured in subjects with age under 30 years (young group) and with more than 60 years (older group).

\begin{tabular}{lccc}
\hline & $\begin{array}{c}\text { Young } \\
(\mathbf{n = 2 0})\end{array}$ & $\begin{array}{c}\text { Older } \\
(\mathbf{n = 2 3})\end{array}$ & P \\
\hline Age (years) & $24 \pm 3$ & $66 \pm 4$ & $<0.0001$ \\
Gender (M/F) & $8 / 12$ & $9 / 14$ & $>0.05$ \\
BMI (kg/cm 2 ) & $23 \pm 3$ & $25 \pm 4$ & 0.8732 \\
Glucose (mg/dL) & $79 \pm 9$ & $84 \pm 7$ & 0.05 \\
Cholesterol (mg/dL) & & & \\
$\quad$ Total & $155 \pm 27$ & $196 \pm 45$ & 0.0010 \\
$\quad$ HDL & $53 \pm 11$ & $48 \pm 12$ & 0.1643 \\
$\quad$ LDL & $88 \pm 19$ & $124 \pm 42$ & 0.0010 \\
Triglycerides (mg/dL) & $58 \pm 24$ & $129 \pm 56$ & $<0.0001$ \\
In vitro lipolysis (AUC) & $5,681 \pm 1,988$ & $7,394 \pm 2,309$ & 0.0133 \\
\hline
\end{tabular}

Data expressed in mean \pm SD. AUC, area under the curve.

In Table 1 , it is also shown that older subjects had higher levels of LDL-cholesterol $(\mathrm{p}<0.001)$ and triglycerides $(\mathrm{p}<0.0001)$ than young subjects, whereas HDL-cholesterol presented no difference between the two groups.

Table 2 shows the compartmental parameters of the young and older groups. The emulsion cholesteryl ester
FCR in older subjects was roughly $50 \%$ lower compared to the young subjects $(0.008 \pm 0.007$ and $0.019 \pm 0.010$ $\min ^{-1}$, respectively, $\mathrm{p}=0.0001$ ). The emulsion triglyceride FCR did not differ in the two groups.

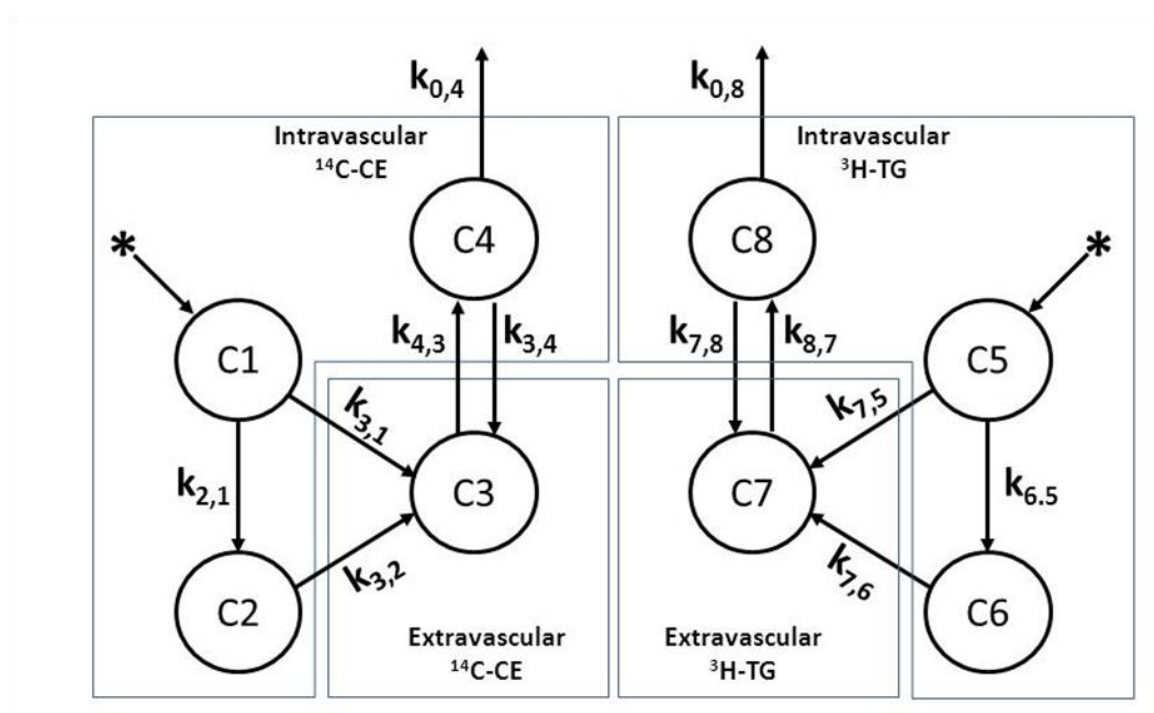

Figure 1. Kinetic model employed for chylomicron-like emulsion metabolism in vivo. The observed data (compartments $\mathrm{C} 1$ and $\mathrm{C} 2$ ) present a biexponential curve. Compartments $\mathrm{C} 1$ - $\mathrm{C} 4$ represent kinetics of ${ }^{14} \mathrm{C}$-cholesteryl oleate $\left({ }^{14} \mathrm{C}\right.$-CE). Compartments $\mathrm{C} 5$ - $\mathrm{C} 8$ represent kinetics of ${ }^{3} \mathrm{H}$-triglycerides $\left({ }^{3} \mathrm{H}-\mathrm{TG}\right)$. Compartments $\mathrm{C} 1$ and $\mathrm{C} 5$ represent emulsion after plasma injection. Compartments $\mathrm{C} 2$ and $\mathrm{C} 6$ represent emulsion after redistribution. Compartments $\mathrm{C} 3$ and $\mathrm{C} 7$ correspond extra-vascular space, mainly the liver, and C4 and C8 the emulsion labeled lipids recirculation. The constants $\mathrm{k}_{\mathrm{i}, \mathrm{j}}\left(\mathrm{min}^{-1}\right)$ represent the fractional catabolic rate $(\mathrm{FCR})$ or transfer from compartment $j$ to compartment $i$ over time. $\mathrm{k} 3,1$ and $\mathrm{k} 7,5$ - fraction of injected emulsion that is removed directly from plasma by the liver and other tissues. k2,1 and k6,5 - emulsion transfer rates to a complex plasma lipoprotein pool. $\mathrm{k} 3,2$ and $\mathrm{k} 7,6$ - removal from the plasma of the emulsion mainly by the liver. k4,3 and $\mathrm{k} 8,7$ - emulsion transfer rates to VLDL (labeled lipids recirculation). $\mathrm{k} 3,4$ and $\mathrm{k} 7,8$ - recirculated lipids removal by the liver. $\mathrm{k} 0,4$ and $\mathrm{k} 0,8$ - output of labeled lipids from the body. 
Table 2. Kinetics and compartmental analysis parameters in subjects with age under 30 years (young group) and with more than 60 years (older group).

\begin{tabular}{lccc}
\hline & $\begin{array}{c}\text { Young } \\
(\mathbf{n = 2 0})\end{array}$ & $\begin{array}{c}\text { Older } \\
(\mathbf{n = 2 3 )}\end{array}$ & P \\
\hline $\mathrm{k} 2,1=\mathrm{k} 6,5$ & $0.134 \pm 9.38 \times 10^{-4}$ & $0.145 \pm 6.45 \times 10^{-4}$ & $<0.0001$ \\
$\mathrm{k} 3,1=\mathrm{k} 7,5$ & $0.150 \pm 2,93 \times 10^{-4}$ & $0.129 \pm 5.88 \times 10^{-4}$ & $<0.0001$ \\
$\mathrm{k} 3,2$ & $0.0216 \pm 0.0097$ & $0.0155 \pm 7.07 \times 10^{-3}$ & 0.0222 \\
$\mathrm{k} 4,3$ & $0.00122 \pm 0.00042$ & $0.00470 \pm 0.00385$ & 0.0071 \\
$\mathrm{k} 3,4$ & $2.72 \times 10^{-6} \pm 0.00996$ & $0.0321 \pm 0.0079$ & $<0.0001$ \\
$\mathrm{k} 0,4$ & $3.74 \times 10^{-7} \pm 0.00448$ & $0.00309 \pm 0.00369$ & 0.0173 \\
$\mathrm{k} 7,6$ & $0.0560 \pm 0.0007$ & $0.0498 \pm 0.0005$ & $<0.0001$ \\
$\mathrm{k} 7,8$ & $0.0578 \pm 0.0045$ & $0.0422 \pm 0.0038$ & $<0.0001$ \\
$\mathrm{k} 8,7$ & $0.00937 \pm 0.00561$ & $0.00939 \pm 0.00471$ & 0.9899 \\
$\mathrm{k} 0,8$ & $4.21 \times 10^{-7} \pm 0.00433$ & $0.0160 \pm 0.0025$ & $<0.0001$ \\
${ }^{4} \mathrm{C}-\mathrm{CE} \mathrm{FCR}\left(\mathrm{min}^{-1}\right)$ & $0.019 \pm 0.010$ & $0.008 \pm 0.007$ & 0.0001 \\
${ }^{3} \mathrm{H}-\mathrm{TG} \mathrm{FCR}\left(\mathrm{min}^{-1}\right)$ & $0.027 \pm 0.014$ & $0.030 \pm 0.017$ & 0.5350 \\
\hline
\end{tabular}

Data expressed in mean \pm SD. $\mathrm{k}_{\mathrm{i}, \mathrm{j}}$ in min $^{-1}$, compartmental parameters as indicated in Fig 1. Fractional clearance rates of the emulsion cholesteryl esters $\left({ }^{14} \mathrm{C}-\mathrm{CE}\right.$ FCR $)$ and triglycerides $\left({ }^{3} \mathrm{H}-\mathrm{TG}\right.$ FCR).

The triglyceride breakdown by lipoprotein lipase, as assayed in vitro, was pronouncedly diminished in older group. Lipolysis was $23 \%$ less in the plasma of older subjects as compared with that of young subjects (AUC $=$ $7,394 \pm 2,309$ and 5,681 $\pm 1,988$, respectively, $\mathrm{p}=0.0001)$ as estimated by the AUC (Table 1).

\section{DISCUSSION}

By means of the chylomicron-like emulsion method, this study shows that in the older subjects the removal of chylomicron remnants from the plasma is delayed when compared to young subjects, as indicated by their lower cholesteryl ester FCR. On the other hand, the chylomicron lipolysis was not diminished in older subjects, as judged by the triglyceride FCR that was the same for both the two groups. In the in vitro assay of post-heparin lipolysis, however, the hydrolysis of the triglycerides was smaller in the older than in the young group. The $\mathrm{k} 3,1$ and $\mathrm{k} 7,5$ in older group represent a lower removal of the emulsion by the fast component. Consequently, more emulsion particles enter the lipoprotein pool as suggested by Schwartz et al [18] and therefore increasing k2,1 and k6,5. The constants $\mathrm{k} 3,2$ and $\mathrm{k} 7,6$, that represent the slow hepatic and other tissue removal component of the decaying curve, were lower in older subjects compared to young subjects and consequently the older subjects presented slow emulsion FCR.

The issue of the plasma lipid postprandial status in the aged had been addressed in previous studies using fat load tests. In this respect, Cohn et al found correlations of the magnitude of postprandial triglyceridemia with age, in 22 subjects of both genders with ranging from 22-79 years
[4]. Krasinski et al showed that in 86 men and women (1976 years), given a fat load supplemented with retinyl ester used as chylomicron remnant label, the AUC in the plasma of the label was significantly greater in the older subjects [19], but Borel et al (1998) found no difference in the AUC in the plasma of the retinyl esters between older and young men aged 20 to 72 years [7]. In contrast, Relas et al reported that the retinyl ester AUC of eight older subjects, aged 78-79 years, was higher than that of six young subjects, aged 22-25 [8]. Puga et al found increased sequential triglyceridemia in 6 older (mean $66.7 \pm 1.1$ years) when compared to 6 young $(22.7 \pm 2.4$ years) subjects [20]. Jackson et al, by comparing middleage with young men (aged $46.7 \pm 1.4$ and $22.3 \pm 0.9$ years, respectively), found that the middle-aged had higher plasma triglyceride AUC after the ingestion of a fat load [21]. These authors separated postprandial triglyceriderich from triglyceride-poor lipoprotein fractions and found differences in incremental triglyceridemia only in the triglyceride-rich fractions. Milan et al found similar AUC of triglyceridemia in older subjects (60-75years) and in young ones (20-25 years) after an oral fat load [22]. They noted that the peak of triglyceride values, however, was delayed in the older subjects as compared with the young subjects [22].

Tests for postprandial plasma lipids suffer from several drawbacks. Chylomicron remnants are difficult to tell apart from liver synthesized VLDLs and retinyl esters ingested to label chylomicrons partially shift from chylomicrons and remnants to other lipoprotein classes $[23,24]$. Apo B48 is the apo B form present in chylomicrons, whereas apo B100 is the apo B form present in VLDL and its catabolic products, is a reliable 
marker for remnant kinetics [24]. However, apo B48 kinetics was not performed in the previous studies focusing chylomicron metabolism and aging. At any rate, several factors that greatly differ among individual subjects and are not directly involved in plasma chylomicron metabolism, such as intestinal motility, intestinal flora interfere with fat intestinal absorption [2]. On the other hand, accumulation of VLDL triglycerides due to competition between chylomicrons and VLDL for lipoprotein lipase sites also occurs, as reported by Karpe et al [23]. All these factors introduce great variability and non-specificity referring to chylomicrons and remnants. Apo B48 determination is commercially available and is routinely measured in fasting serum. In this setting, it is difficult to ascertain whether apo B48 levels reflect chylomicron remnant catabolism, but the higher fasting levels of this protein are related with the presence of coronary artery disease [25]. The action of lipoprotein lipase is stimulated by apo C-II and inhibited by apo C-III, but it has been reported that the relation of serum apo C-II/apo C-III is not changed by aging [26].

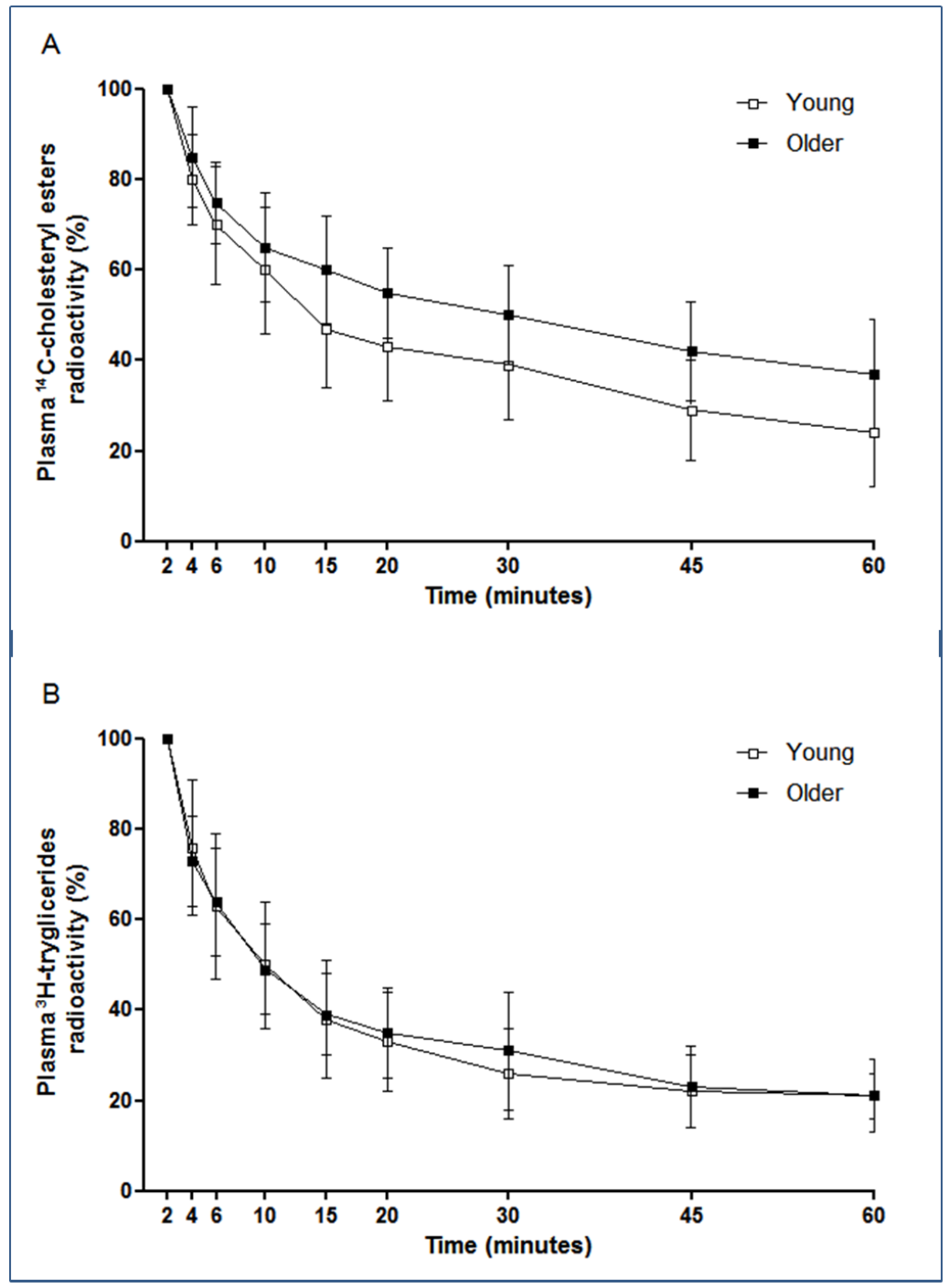

Figure 2. Plasma decay curve of the emulsion cholesteryl esters (A) and triglycerides (B) in healthy subjects with age under 30 years (young) and those with age above 60 years (older). The chylomicron-like emulsion labeled with the radioactive lipids was injected intravenously after a 12 hour fast. Plasma samples were taken at regular intervals over 60 minutes to determine the radioactivity remaining in the plasma in a scintillation solution.

In the chylomicron-like emulsion method, the labeled emulsions are injected into the plasma compartment, bypassing the intestinal absorption component. Injected after a $12 \mathrm{~h}$ fast, interfering processes such as competition with VLDL are avoided and the blood sampling period is shortened [12]. The accumulation of VLDL remnants in the postprandial state, as described by Nakajima et al [27], which interferes with the analysis of chylomicron catabolism in fat load tests, is not at play in the current experimental 
conditions, wherein the chylomicron-like emulsion kinetics is determined in the fast state. The emulsion method is straightforward, allowing precise calculation of the decaying parameters by compartmental analysis $[10,11,12,13]$. With this approach, remnants are removed from the plasma of the older subjects nearly $50 \%$ slower than in the young subjects. This is probably related with the decreased expression of LDL receptors (LDLR) in the liver that occurs in older subjects, leading to diminished LDL clearance and higher LDLcholesterol levels [12]. LDLR do not only remove LDL but is also actively involved in chylomicron remnant uptake by the liver $[28,29]$. Other mechanisms are also involved in the remnant uptake by the liver. LRP1 (LDL receptor-related protein) and heparan sulfate proteoglycans (HSPGs) facilitate the rapid hepatic clearance of remnants, using apo $\mathrm{E}$ as ligand. Remnant particles penetrate the fenestrated endothelium in the liver and bind to lipoprotein receptors or HSPGs in the space of Disse, being subsequently internalized into the hepatocytes (for review, see Ref 6).

In this regard, we found a correlation between LDL-cholesterol and FCR of the chylomicron-like emulsion cholesteryl esters [12]. Most importantly, the fact that the residence times of native chylomicrons and chylomicron-like emulsions are similar, as shown by Park et al [30], suggests that the role of apo B48 in the uptake of remnants is not relevant. This role exerted by apo $\mathrm{E}$ that is present in both native and artificially-made chylomicrons.

It is of note that there was no lipolysis decrease in the older subjects, as evaluated in vivo by the emulsion triglyceride kinetics. However, the in vitro method showed that lipolysis was decreased in the older subjects compared with the young subjects, similar to the in vitro lipolysis results obtained by Jackson et al [21]. Since in vitro lipolysis is measured in post-heparin plasma, this discrepancy can be ascribed, among other causes, to agerelated differences in the dissociation of lipoprotein lipase molecules from the endothelium to which the enzyme is bound by heparan sulfate bridges.

It should be pointed out that a limitation of the study was that the older group of subjects had higher LDLcholesterol and triglycerides than the young group. This could have had influenced the emulsion kinetic results. However, it is well known that those plasma lipids systematically increase with increasing age [26]. It is also worthwhile mentioning that both groups had plasma lipids within the recommended values. Pairing the two groups for plasma lipids could then disrupt the true value of the study.

As documented by the apo B48 kinetics following a standard fatty meal [24] and by the chylomicron-like emulsion method [12], delayed removal of remnants is associated with the presence of coronary artery disease and with the evolution and clinical manifestations of this disease. Thus, the delayed remnant removal documented here by kinetic analysis may have important implications for the understanding of the atherosclerosis process that is accelerated and has become more frequently manifested in aging subjects.

\section{Acknowledgments}

This study was supported by the São Paulo State Research Support Foundation (FAPESP, São Paulo, Brazil). Dr. Maranhão has a Research Carrier Award from the National Council for Scientific and Technological Development (CNPq, Brasilia, Brazil). The authors wish to thank Mr. William A. Presada for the English revision of the text.

\section{Conflicts of Interest}

The authors declare that they have no conflicts of interest.

\section{References}

[1] Redgrave TG (1970). Formation of cholesteryl esterrich particulate lipid during metabolism of chylomicrons. J Clin Invest, 49:465-71.

[2] Lambert JE, Parks EJ (2012). Postprandial metabolism of meal triglyceride in humans. Biochim Biophys Acta, 1821:721-6.

[3] Wilhelm MG, Cooper AD (2003). Induction of atherosclerosis by human chylomicron remnants: a hypothesis. J Atheroscler Thromb, 10:132-9.

[4] Cohn JS, McNamara JR, Cohn SD, Ordovas JM, Schaefer EJ (1988). Postprandial plasma lipoprotein changes in human subjects of different ages. J Lipid Res, 29: 469-79.

[5] Cassader M, Gambino R, Ruiu G, Marena S, Bodoni P, Pagano G (1996). Postprandial triglyceride-rich lipoprotein changes in elderly and young subjects. Aging (Milano), 8: 421-8.

[6] Dallinga-Thie GM, Franssen R, Mooij HL, Visser ME, Hassing HC, Peelman F, et al. (2010). The metabolism of triglyceride-rich lipoproteins revisited: new players, new insight. Atherosclerosis, 211(1):1-8.

[7] Borel P, Mekki N, Boirie Y, Partier A, AlexandreGouabay MC, Grolier P, et al. (1998). Comparison of the postprandial plasma vitamin A response in young and older adults. J Gerontol A Biol Sci Med Sci, 53: B133-40.

[8] Relas H, Gylling H, Rajaratnam RA, Miettinen TA (2000). Postprandial retinyl palmitate and squalene metabolism is age dependent. J Gerontol A Biol Sci Med Sci, 55:B515-21. 
[9] Hirata MH, Oliveira HC, Quintão EC, Redgrave TG, Maranhão RC (1987). The effects of Triton WR-1339, protamine sulfate and heparin on the plasma removal of emulsion models of chylomicrons and remnants in rats. Biochim Biophys Acta, 917:344-6.

[10] Maranhão RC, Feres MC, Martins MT, Mesquita $\mathrm{CH}$, Toffoletto O, Vinagre CG, et al. (1996). Plasma kinetics of a chylomicron like emulsion in patients with coronary artery disease. Atherosclerosis, 126:15-25.

[11] Vinagre CG, Stolf NA, Bocchi E, Maranhão RC. (2000). Chylomicron metabolism in patients submitted to cardiac transplantation. Transplantation, 69(4):5327.

[12] Sposito AC, Santos RD, Hueb W, Ventura LI, Vinagre CG, Ramires JA, et al. (2002). LDL concentration is correlated with the removal from the plasma of a chylomicron-like emulsion in subjects with coronary artery disease. Atherosclerosis, 161:447-53.

[13] Mangili OC, Moron Gagliardi AC, Mangili LC, Mesquita $\mathrm{CH}$, Machado Cesar LA, Tanaka A, et al (2014). Favorable effects of ezetimibe alone or in association with simvastatin on the removal from plasma of chylomicrons in coronary heart disease subjects. Atherosclerosis, 233 (1): 319-25

[14] Redgrave TG, Zech LA (1987). A kinetic model of chylomicron core lipid metabolism in rats: the effect of a single meal. J Lipid Res, 28: 473-82.

[15] ICRP Publication 113 (2009). Education and training in radiological protection for diagnostic and interventional procedures. Ann ICRP, 39:7-68.

[16] Ehnholm C, Kuusi T (1986). Preparation, characterization, and measurement of hepatic lipase. Methods Enzymol, 129:716-38.

[17] Vinagre JC, Vinagre CC, Pozzi FS, Zácari CZ, Maranhão RC (2014). Plasma kinetics of chylomicronlike emulsion and lipid transfers to high-density lipoprotein (HDL) in lacto-ovo vegetarian and in omnivorous subjects. Eur J Nutr, 53:981-7.

[18] Schwartz CC, Vanden Broek JM, Cooper PS (2004). Lipoprotein cholesteryl ester production, transfer, and output in vivo in humans. J Lipid Res, 45: 1594-607.

[19] Krasinski SD, Cohn JS, Schaefer EJ, Russell RM (1990). Postprandial plasma retinyl ester response is greater in older subjects compared with younger subjects. Evidence for delayed plasma clearance of intestinal lipoproteins. J Clin Invest, 85(3):883-92.

[20] Puga GM, Meyer C, Everman S, Mandarino LJ, Katsanos CS (2011). Postprandial lipemia in the elderly involves increased incorporation of ingested fat in plasma free fatty acids and small (Sf 20-400) triglyceride-rich lipoproteins. Am J Physiol Endocrinol Metab, 301, E356-61.

[21] Jackson KG, Knapper-Francis JM, Morgan LM, Webb DH, Zampelas A, Williams CM (2003). Exaggerated postprandial lipaemia and lower post-heparin lipoprotein lipase activity in middle-aged men. Clin Sci (Lond), 105: 457-66.

[22] Milan AM, Nuora A, Pundir S, et al (2016). Older adults have an altered chylomicron response to a highfat meal. Br J Nutr, 115:791-9.

[23] Karpe F, Steiner G, Olivecrona T, Carlson LA, Hamsten A (1993). Metabolism of triglyceride-rich lipoproteins during alimentary lipemia. J Clin Invest, 91:748-58.

[24] Cohn JS, Johnson EJ, Millar JS, Cohn SD, Milne RW, Marcel YL, et al. (1993). Contribution of apo B48 and apo B100 triglyceride-rich lipoproteins (TLR) to postprandial increases in the plasma concentration of TRL triglycerides and retinyl esters. J Lipid Res, 34: 2033-40.

[25] Karpe F, Hellénius ML, Hamsten A (1999). Differences in postprandial concentrations of very-lowdensity lipoprotein and chylomicron remnants between normotriglyceridemic and hypertriglyceridemic men with and without coronary heart disease. Metabolism, 48: 301-7

[26] Takeuchi N, Matsumoto A, Katayama Y, Arao M, Koga M, Nakao H, et al. (1983). Changes with aging in serum lipoproteins and apolipoprotein $\mathrm{C}$ subclasses. Arch Gerontol Geriatr, 2(1-2): 41-8.

[27] Nakajima K, Nakano T, Tokita Y, Nagamine T, Inazu A, Kobayashi J, et al. (2011). Postprandial lipoprotein metabolism: VLDL vs chylomicrons. Clin Chim Acta. 412(15-16): 1306-18.

[28] Marino M, Pallottini V, D’Eramo C, Cavallini G, Bergamini E, Trentalance A (2002). Age-related changes of cholesterol and dolichol biosynthesis in rat liver. Mech Ageing Dev, 123:1183-9

[29] de Faria E, Fong LG, Komaromy M, Cooper AD (1996). Relative roles of the LDL receptor, the LDL receptor-like protein, and hepatic lipase in chylomicron remnant removal by the liver. J Lipid Res, 37: 197-209.

[30] Park Y, Damron BD, Miles JM, Harris WS. (2001). Measurement of human chylomicron triglyceride clearance with a labeled commercial lipid emulsion.

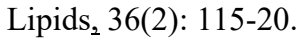

